\title{
Ácido indolbutírico (AIB) e substratos na propagação vegetativa de Jatobá (Hymenaea courbaril L.) por miniestaquia
}

\author{
Luciana Coelho Moura $^{1 *}$ Miranda Titon ${ }^{2}$ Cristiane Coelho Moura ${ }^{2}$ Cibele Chaves Souza ${ }^{3}$ Reynaldo Campos \\ Santana ${ }^{2}$
}

${ }^{1}$ Universidade Federal de Mato Grosso, Av. Fernando Corrêa da Costa, 2367 - Boa Esperança, Cuiabá - MT, 78060-900

${ }^{2}$ Universidade Federal dos Vales do Jequitinhonha e Mucuri, Rodovia MG 367 - Km 583, n 5000, Bairro Alto da Jacuba, Diamantina-MG, $39100-000$

${ }^{3}$ Agroflor Engenharia e Meio Ambiente, Av. Bernardes Filho, 31 - Lourdes, Viçosa - MG, 36570-000

*Author for correspondence: coelho.moura.luciana@gmail.com

Received: April 2018 / Accepted: February 2019 / Published: March 2019

\section{Resumo}

O objetivo do presente trabalho foi avaliar o potencial de enraizamento e crescimento de miniestacas de Hymenaea courbaril L., sob o efeito de diferentes concentrações de ácido indolbutírico (AIB) e diferentes substratos. Miniestacas foram retiradas do ápice de mudas seminais, tratadas com AIB líquido nas concentrações de 0, 1000, 2000, 4000 e $6000 \mathrm{mg} . \mathrm{L}^{-1}$ e estaqueadas nos substratos comercial Bioplant ${ }^{\circledR}$ e no composto de $40 \%$ de vermiculita, $30 \%$ de casca de arroz carbonizada e $30 \%$ de fibra de coco, organizado em um esquema fatorial $5 \times 2$ (5 concentrações de AIB e 2 substratos). Os dados foram obtidos aos 60 e 120 dias de idade e expressos em percentual de enraizamento, número de raízes, comprimento da maior raiz, peso da matéria seca radicular, percentual e classificação da calosidade, percentual de sobrevivência, percentual de brotações, crescimento em altura e diâmetro do coleto, peso da matéria seca aérea e índice de qualidade de Dickson. O substrato composto de $40 \%$ de vermiculita, $30 \%$ de casca de arroz carbonizada e $30 \%$ de fibra de coco mostrou-se eficiente para o enraizamento e crescimento de miniestacas de $H$. courbaril.. Não é necessário o uso do regulador de crescimento AIB na propagação vegetativa de miniestacas dessa espécie a partir de mudas seminais. A miniestaquia de H. courbaril, a partir de mudas seminais, é um método viável, tornando-se uma alternativa para produção de mudas dessa espécie durante todo o ano, principalmente nas situações em que a semente é insumo limitante.

Palavras-chave: Espécie nativa, Auxina, Bioplant ${ }^{\circledR}$, Vermiculita, Casca de arroz carbonizada, Enraizamento adventício

\section{Introdução}

Dentre as espécies do Cerrado bastante exploradas para uso comercial, encontra-se o jatobá (Hymenaea courbaril L.). Árvore da família Fabaceae, subfamília Caesalpinioideae, que pode atingir 30 a $45 \mathrm{~m}$ de altura com diâmetro à altura do peito de até $2 \mathrm{~m}$, ocorre em grande parte do Brasil (Flora do Brasil em construção, 2020).

O interesse pela espécie é inerente dos seus diversos usos. A madeira de $H$. courbaril pode ser empregada na construção civil, marcenaria, peças torneadas, instrumentos musicais e laminados (Flora do Brasil em construção, 2020). Possui propriedades medicinais, indicada no tratamento de asma, blenorragia, bronquite, cólica, coqueluche, e a farinha, endocarpo que envolve as sementes, é valorizada pelo seu excelente perfil nutricional (Soares et al. 2016).

O plantio de essências nativas, seja com finalidade econômica ou conservacionista, requer uma série de cuidados que dependem do conhecimento prévio de suas características fisiológicas e exigências ecológicas nas diversas etapas de seu ciclo vital (Almeida et al. 2004). Para a exploração racional das potencialidades das espécies nativas, é de suma importância o estudo da propagação das mesmas, bem como a melhor maneira de se conduzir a produção de mudas.

A produção contínua de mudas por semente de $H$. courbaril ao longo do ano pode ser prejudicada pela disponibilidade de sementes, pois, segundo Rossi (2008), a viabilidade de armazenamento das sementes é curta, não ultrapassando quatro meses. Com crescimento vegetativo lento e sementes com de tegumento impermeável à água, que dificultam e retardam a germinação, a produção seminal de mudas de $H$. courbaril pode tornar-se bastante lenta e onerosa (Gomer et al. 2013; Cruz e Pereira 2015). A técnica de miniestaquia representa uma alternativa para produção de mudas de espécies florestais, principalmente nas situações em que a semente é insumo limitante (Xavier et al. 2013).

Para a propagação de $H$. courbaril, Pereira et al. (2017) apontaram dosagens de hormônio do ácido indolbutirico (IBA) sobre enraizamento e sobrevivência de estacas, porém não foram encontrados na literatura trabalhos abordando a propagação vegetativa via miniestaquia, de forma que a definição dessa metodologia em viveiro constitui uma demanda promissora para a produção de mudas da espécie.

O sucesso da miniestaquia somente é possível mediante a manipulação das condições ambientais e fisiológicas das estacas, as quais propiciam a desdiferenciação dos tecidos, e, finalmente, a formação de raízes adventícias (Hartman et al. 2011). Aplicações exógenas de auxinas proporcionam maior percentagem, velocidade, qualidade e uniformidade de enraizamento (Hartman et al. 2011), a exemplo do ácido indolbutírico (AIB), auxina sintética mais utilizada no enraizamento de estacas, por se tratar de uma substância fotoestável, de ação localizada e menos sensível à degradação biológica (Taiz e Zeiger 2017).

O tipo de substrato é também um dos aspectos que devem ser pesquisados para se garantir a produção de mudas de boa qualidade, pois desempenha importante função no processo de miniestaquia, basicamente por proporcionar sustentação às estacas, mantendo na sua base um ambiente úmido, escuro e eficientemente aerado (Hartmann et al. 2011). Segundo Xavier et al. (2013), diversas são as opções de substratos, sendo os mais comuns nos viveiros de produção de mudas a areia, turfa, a serragem semidecomposta, casca de arroz carbonizada, o composto orgânico, a terra de subsolo, a fibra de coco, vermiculita e a mistura entre eles.

A avaliação da eficiência da miniestaquia para $H$. courbaril L., contribuirá para a ampliação dos conhecimentos dos processos de produção de mudas desta espécie, suportando a base para uma silvicultura para fins comerciais e gerando mais um aporte econômico para o país. Neste contexto, o objetivo desse trabalho foi avaliar o potencial de enraizamento e crescimento de miniestacas de Hymenaea courbaril L., provenientes de mudas seminais, 
sob o efeito de diferentes concentrações de ácido indolbutírico (AIB) e substratos.

\section{Material e Métodos}

\section{Material experimental}

O trabalho foi realizado, entre os meses de maio a agosto, no Centro Integrado de Propagação de Espécies Florestais do Departamento de Engenharia Florestal da Universidade Federal dos Vales do Jequitinhonha e Mucuri - UFVJM, Diamantina, Minas Gerais, Brasil.

As miniestacas caulinares foram retiradas do ápice de mudas de $H$. courbaril e padronizadas com aproximadamente $5 \mathrm{~cm}$ de altura, contendo uma a duas folhas e redução de $50 \%$ da área foliar (Figura 2A). As mudas, produzidas, via seminal e com 3 meses de idade, foram provenientes de sementes coletadas em dez matrizes no município de Mendanha, Minas Gerais, Brasil.

Após podadas, as mudas constituíram as minicepas, sendo então estabelecidas num minijardim clonal (Figura 1A), em sacos de polietileno ( $3 \mathrm{~L}$ ) contendo areia e composto orgânico. Cada saso de polietileno continha uma minicepa. Foram mantidas em área de rustificação ao nível do solo, com 8 irrigações diárias e aplicação quinzenal alternada dos fungicidas comerciais Orius 250 EC Orthocide 500 (Captan) e Cuprogarb. A adubação aplicada às minicepas, via fertirrigação, composta por macro e micro nutrientes $\left(2,0\right.$ g.L. $\mathrm{L}^{-1}$ de super fosfato simples; 0,9 g.L. $\mathrm{L}^{-1}$ de fosfato monoamônio; 1,5 g. $\mathrm{L}^{-1}$ de sulfato de magnésio; 2,63 g. $\mathrm{L}^{-1}$ de cloreto de potássio; 7,5 g.L $\mathrm{L}^{-1}$ de sulfato de amônia; 0,035 g.L. $\mathrm{L}^{-1}$ de ácido bórico; 0,004 g.L $\mathrm{L}^{-1}$ de sulfato de cobre; 0,015 g.L $\mathrm{L}^{-1}$ sulfato de zinco; 0,017 g.. $\mathrm{L}^{-1}$ de sulfato de manganês e 0,02 g.L. $\mathrm{L}^{-1}$ de ferrilene), aplicada parceladamente na dosagem de 10 a $12 \mathrm{ml}$ por planta, uma vez por semana.

\section{Regulador de Crescimento e Substratos utilizados}

As miniestacas de jatobá foram tratadas com o regulador de crescimento AIB líquido nas concentrações de 0, 1000, 2000, 4000 e 6000 mg.L - $^{-1}$ e estaqueadas nos substratos Bioplant ${ }^{\circledR}$ (BIO), e na mistura de $40 \%$ de vermiculita, $30 \%$ de casca de arroz carbonizada e 30\% de fibra de côco (VCF) (Figura 1B). As características físicas dos substratos estão apresentadas na tabela 1 .

As miniestacas tiveram sua base mergulhada por 10 segundos na solução auxínica sendo, em seguida, estaqueadas em casa de vegetação. Utilizou-se tubetes plásticos de $210 \mathrm{~cm}^{3}$ contendo os diferentes substratos misturados a 7 g.L. ${ }^{-1}$ de formulado de liberação controlada Osmocote ${ }^{\circledR}$. As miniestacas permaneceram em casa de vegetação por 105 dias, sendo posteriormente transferidas para casa de sombra com $50 \%$ de sombreamento, onde foram mantidas por mais 15 dias.

\section{Delineamento Experimental e Análise de Dados}

Foi utilizado o delineamento experimental inteiramente casualizado em esquema fatorial $5 \times 2$ (5 concentrações de AIB e 2 substratos), com 4 repetições e 10 miniestacas por repetição.

Aos 60 dias avaliou-se o enraizamento das miniestacas, quando foram determinados o percentual de enraizamento (ENR60); o número de raízes ( $\geq 2 \mathrm{~mm}$ de comprimento) por miniestaca (NR60); e o comprimento da maior raiz por miniestaca (CMR60). As miniestacas não enraizadas tiveram sua calogênese total (CT60) classificada em baixa (BC60), e alta calogênese (AC60). Para esta avaliação foram utilizadas $50 \%$ das miniestacas de cada repetição.

Ainda aos 60 dias de idade, avaliou-se o percentual de sobrevivência (SOB60) e o percentual de miniestacas com brotações (BROT60).

Avaliou-se aos 120 dias o percentual de enraizamento (ENR120), o número de raízes ( $\geq 2 \mathrm{~mm}$ de comprimento) por miniestaca (NR120), o comprimento da maior raiz por miniestaca (CMR120), o peso médio da matéria seca radicular (PMSR120) e da parte aérea (PMSPA120), a calosidade total (CT120), o percentual de sobrevivência (SOB120), a altura média (H120) e o diâmetro médio do coleto (DC120) das miniestacas remanescentes. Para obtenção do PMSR120 e PMSPA120, o material vegetal aéreo e radicular foram secos em estufa de secagem com circulação e renovação de ar a $65^{\circ} \mathrm{C}$ por 48 horas, e, em seguida pesada em balança de precisão.

A qualidade das mudas foi avaliada utilizando-se do índice de qualidade de Dickson (IQD), que foi determinado em função da altura da parte aérea $(\mathrm{H})$, do diâmetro do coleto (DC), do peso de matéria seca da parte aérea (PMSPA) e do peso de matéria seca das raízes (PMSR), por meio da fórmula (Dickson et al., 1960): $\mathrm{IQD}=\mathrm{MST} /((\mathrm{H} / \mathrm{D})+(\mathrm{MSPA} / \mathrm{MSR}))$.

A análise dos dados foi realizada através de análise de variância e análise descritiva, com o auxílio do programa estatístico R, versão 3.0.3 (R Core Team, 2014) e o pacote ExpDes (Experimental Designs) (Ferreira et al. 2013).

\section{Resultados e discussão \\ Comportamento das miniestacas aos 60 dias de idade}

Aos 60 dias não foram observadas diferenças estatísticas significativas $(\mathrm{P}>0,05$ pelo teste $\mathrm{F})$ para as características avaliadas em função das concentrações de AIB e dos substratos.

Em geral, o ENR60 foi baixo (Figuras 1E e 2A), não ultrapassando $30 \%$, e o substrato VCF foi superior ao BIO em termos da eficiência de enraizamento. Um dos fatores que pode ter contribuído para os baixos percentuais de enraizamento foi a baixa temperatura observada durante a condução do experimento, uma vez que o mesmo foi conduzido durante o inverno. Todas as atividades metabólicas e fisiológicas das plantas são reguladas pelo nível de energia calorífica existente no sistema, geralmente medida por meio da temperatura (Hartman et al. 2011).

Para o substrato BIO, houve um aumento progressivo do enraizamento até a concentração de $2000 \mathrm{mg} . \mathrm{L}^{-1}$, que diminuiu a partir desse valor. Essa tendência se repetiu para o substrato VCF, com exceção da concentração $6000 \mathrm{mg} . \mathrm{L}^{-1}$, que teve valor superior à concentração de $4000 \mathrm{mg} . \mathrm{L}^{-1}$ (Figura 2A).

Quanto às características NR60, CTR60 e CMR60 segue-se essa mesma tendência de crescimento até a concentração de $2000 \mathrm{mg} . \mathrm{L}^{-1}$ e posterior decréscimo a partir desse valor para o substrato VCF. Para o substrato BIO, a tendência foi mantida, porém o pico se deu na concentração de $1000 \mathrm{mg} . \mathrm{L}^{-1}$ para as mesmas características (Figuras 2B, $2 \mathrm{C}$ e 2D). Essa tendência pode ser explicada, por se tratar de material juvenil, no qual o balanço hormonal interno mostrase favorável ao enraizamento, podendo ocorrer, em certas condições, resposta negativa às aplicações hormonais adicionais (Xavier et al. 2013).

Os níveis de classificação da calogênese de miniestacas estão ilustrados nas Figuras 1C e 1D. Em termos de CT60, os valores foram altos para os dois substratos, chegando a $95 \%$ para a concentração de $2000 \mathrm{mg} . \mathrm{L}^{-1}$ no substrato BIO e $85 \%$ para a concentração $1000 \mathrm{mg} . \mathrm{L}^{-1}$ no substrato VCF (Figuras 2E e 2F). Para os níveis de classificação, o substrato VCF teve valores equilibrados entre CB60 e CA60, contrapondo o substrato BIO, que apresentou maior CB60.

A formação de calos na base da miniestaca pode ser um indício de enraizamento futuro, caso as estacas permaneçam por mais tempo em casa de vegetação, pois, em espécies consideradas de difícil enraizamento geralmente há 
formação de calos precedendo a formação de raízes (Hartmann et al. 2011).

Com relação à $\mathrm{SOB} 60$, em todas as concentrações de AIB, verificou-se sobrevivência superior a $94 \%$ das miniestacas para o substrato VCF e $89 \%$ para o substrato BIO (Figura 2H). Essa resposta está de acordo com resultados obtidos na miniestaquia de outras espécies nativas, como: Ilex paraguariensis (Wendling et al. 2007), Calophyllum brasiliense (Ciriello e Moru 2015), Schizolobium amazonicum (Dias et al. 2015a), Anadenanthera macrocarpa (Dias et al. 2015b), Araucaria Angustifólia (Pires et al. 2015).

Para o substrato BIO, o BROT60 foi maior nas concentrações de 0 e 6000 mg.L-1 (Figura 2G). Essas concentrações foram as que apresentaram menores percentuais de enraizamento, número de raízes, comprimento total de raízes e comprimento da maior raiz, indicando uma relação negativa entre emissão de brotações e enraizamento.

Em geral, o percentual de ENR60 foi maior para o substrato BIO, o que confirma reação contrária ao enraizamento. É possível que as giberelinas causem estímulo ao crescimento vegetativo, competindo com a formação de raízes, sobre as quais tem efeito inibitório (Hartmann et al. 2011). Oliveira (2002) relatou que o enraizamento de estacas lenhosas de pessegueiro foi prejudicado pela brotação ocorrida, competindo com as raízes pelas reservas da estaca

\section{Comportamento das miniestacas aos 120 dias de idade}

Aos 120 dias de idade, as miniestacas de $H$. courbaril apresentaram um bom desempenho no enraizamento (Figuras 1F). Foram observadas diferenças significativas (P $<0,05$ pelo teste $F$ ) entre os substratos sobre algumas características avaliadas aos 120 dias. Para o ENR120 o substrato VCF foi superior ao BIO, com $74 \%$ e $53 \%$ de enraizamento respectivamente. Também se observou superioridade do substrato VCF para o CTR120, PMSR120 e IQD120.

O substrato Bioplant ${ }^{\circledR}$ possui alta capacidade de retenção de umidade (Tabela 1), podendo proporcionar até o apodrecimento de raízes em espécies não tolerantes a alta umidade. Esse fato pode ter reduzido a capacidade de enraizamento de $H$. courbaril no substrato BIO, já que, a espécie é pouco exigente à umidade do solo e geralmente ocorre em terrenos bem drenados (Carvalho 2003).

Em contrapartida, o substrato VCF mostrou-se eficiente para a propagação vegetativa de $H$. courbaril, o que pode ser explicado principalmente pela presença da casa de arroz carbonizada. Schimitz et al. (2002) observaram que a adição de casca de arroz carbonizada à turfa, induziu a redução do excesso de água, amenizando os problemas com excesso de umidade apresentados por esse material orgânico. Outra vantagem do substrato VCF é a adição da vermiculita, que favorece a aeração do sistema radicular (Gomes et al. 2002).
Gonzaga et al. (2016) observaram um melhor crescimento de $H$. courbaril acrescentando areia à terra de subsolo como forma de aeração do substrato. Fachinello et al. (2005) comentam que a vermiculita é cada vez mais utilizada como substrato para o enraizamento de estacas devido à elevada porosidade e à boa retenção de umidade, características altamente desejáveis no processo de enraizamento adventício.

Além disso, Vazques e Mesquita (2003) afirmam que o uso de vermiculita proporcionou uma melhor distribuição e conformação de raízes de Ixora coceina, o que também foi observado para as miniestacas de $H$. courbaril nesse estudo, através da expressiva massa seca de raiz obtida no substrato à base de vermiculita (VCF). Vale ressaltar que o peso da massa seca de raiz está diretamente correlacionado com o volume e quantidade de raízes, fatores primordiais para o melhor desenvolvimento das mudas após o transplantio a campo (Dias et al. 2015b). Tracz et al. (2009) observaram na propagação vegetativa de Bactris gasipaes que os substratos contendo vermiculita em sua composição apresentaram médias de sobrevivência e enraizamento das estacas superiores àquelas cultivadas nos substratos orgânicos puros. Brondani et al. (2007), estudando estaquia de erva-mate, encontrou melhores resultados com o uso da mistura de casca de arroz carbonizada + substrato para enraizamento à base de casca de pinus e vermiculita.

Semelhante à avaliação realizada aos 60 dias, as características analisadas aos 120 dias não apresentaram diferenças significativas ( $\mathrm{P}>0,05$ pelo teste $\mathrm{F}$ ) em função das concentrações de AIB. Em estudo com Paulownia fortunei (Stuepp et al., 2015), com Eugenia uniflora (Pena et al. 2015) e com Tectona grandis (Badilla et al. 2016) foi observado não ser necessário o emprego de reguladores de crescimento para o enraizamento de estacas, assim como Nickinich et al. (2013) e Wendling e Brondani (2015), que não observaram aumento significativo no enraizamento de estacas de Tibouchina fothergillae e Araucaria angustifolia e, respectivamente, sob condições controladas com a aplicação de AIB.

Entretanto, o ENR120 teve uma tendência geral decrescente à medida que se aumentou a concentração de AIB aplicada às miniestacas (Figura $3 \mathrm{~A}$ ), com exceção para as concentrações de 2000 e $4000 \mathrm{mg} . \mathrm{L}^{-1}$ no substrato VCF, que foram igual e pouco superior à testemunha $\left(0 \mathrm{mg} \cdot \mathrm{L}^{-1} \mathrm{de}\right.$ AIB) respectivamente. Portanto, não se justifica a aplicação onerosa do AIB, já que não há a necessidade do uso da auxina na miniestaquia de $H$. courbaril L. Outras avaliações do sistema radicular, como o NR120, o CMR120 e o PMSR120 (Figuras 3B, 3C e 3D) confirmam esse resultado, já que os valores encontrados para a testemunha foram superiores, iguais ou bem próximos aos valores encontrados com a aplicação do regulador de crescimento, não sendo vantajoso gastos com a adição do AIB. 

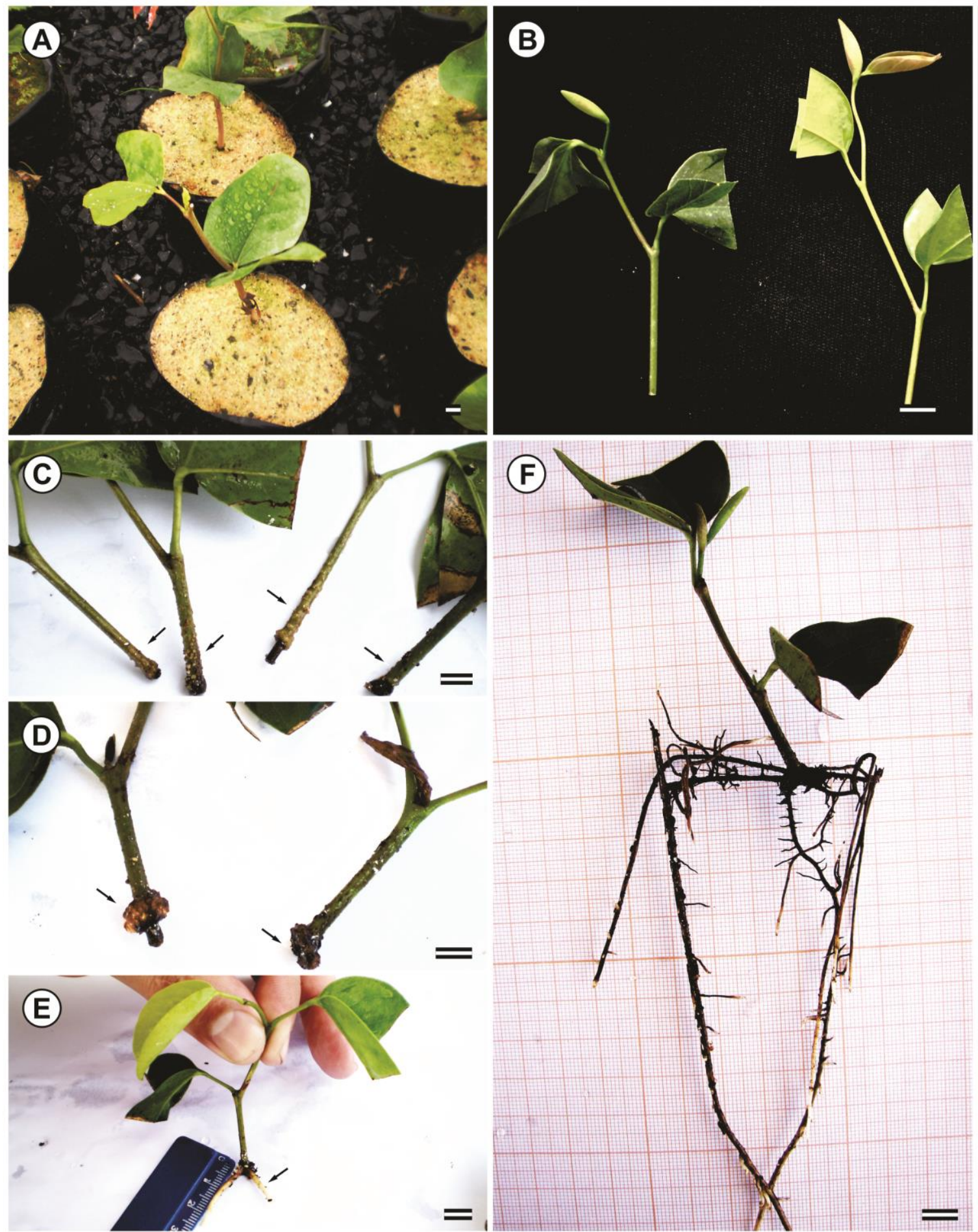

Figura 1- Minijardim clonal (A); miniestacas caulinares com redução foliar (B); classificação de miniestacas não enraizadas em baixa (C) e alta calogênese (D), as setas indicam os pontos de desdiferenciação celular; miniestaca enraizada aos 60 dias (E), a seta indica a raiz; miniestaca enraizada aos 120 dias (F) da espécie Hymenaea courbaril L. As barras equivalem $1,0 \mathrm{~cm}$.

Tabela 1 - Características físicas dos substratos Bioplant ${ }^{\circledR}$ (BIO) e da mistura de $40 \%$ de vermiculita (V), 30\% de casca de arroz carbonizada (C) e $30 \%$ de fibra de côco (F) (VCF)

\begin{tabular}{lcc} 
& \multicolumn{2}{c}{ Substrato } \\
Característica & $\begin{array}{c}\text { Bioplant }{ }^{\circledR} \\
\text { (BIO) }\end{array}$ & $\begin{array}{l}\text { 40V+30C+30F } \\
\text { (VCF) }\end{array}$ \\
\hline Porosidade Total (\%) & 80,58 & 69,83 \\
Macroporosidade (\%) & 34,66 & 37,7 \\
Microporosidade (\%) & 45,92 & 32,13 \\
$\begin{array}{l}\text { Densidade aparente }\left(\mathrm{g} . c m^{-3}\right) \\
\text { Capacidade máxima de }\end{array}$ & 0,11 & 0,11 \\
retenção de água $\left(\mathrm{mL} .55 \mathrm{~cm}^{-3}\right)$ & 25,26 & 17,67 \\
\hline
\end{tabular}

No geral, o ENR120 foi superior ao ENR60, com valores de $75 \%$ e $15 \%$ para as testemunhas $\left(0 \mathrm{mg} . \mathrm{L}^{-1} \mathrm{de}\right.$ AIB), respectivamente, considerando os dois substratos em conjunto (Figuras 2E, 2F e 3A). Nota-se também que a permanência das miniestacas na casa de vegetação por 105 dias foi satisfatório para o enraizamento de miniestacas de H. courbaril. Endres et al. (2007) trabalhando Caesalpinia echinata, observaram que o tempo de permanência das estacas sob nebulização deve ser superior a 120 dias, visto que grande parte das estacas sobreviventes não apresentaram calos ou raízes. Outro fator determinante nesse resultado 
crescente de enraizamento foi o aumento da temperatura entre a avaliação realizada aos 60 e 120 dias, o que segundo Brondani et al. (2007) pode regular a emissão de raízes adventícias sendo importante que o seu desenvolvimento preceda o da parte aérea.

O tempo para enraizamento das miniestacas de $H$. courbaril foi superior ao tempo médio de enraizamento de eucalipto, em média 20 a 40 dias em casa de vegetação (Xavier et al., 2013). Entretanto, o eucalipto é uma espécie de rápido crescimento e diversos estudos já foram realizados para aprimoramento da miniestaquia desta espécie (Gomes et al., 2002; Souza et al., 2014; Correia et al., 2015; Freitas et al., 2017), bem diferente de $H$. courbaril, que se trata de uma espécie de crescimento lento e não existem estudos sobre miniestaquia e a indução de raízes adventícias para esta espécie. Apesar do longo tempo em que as miniestacas permaneceram em casa de vegetação no presente estudo (105 dias), não foram observadas doenças ou deficiências nutricionais nas miniestacas, fato que pode ser comprovado pelas altos valores de sobrevivência ao final do experimento (Figura 3F). Ainda assim, novos estudos podem ser realizados para aprimoramento da técnica da miniestaquia para $H$. courbaril, no intuito de torná-la economicamente viável para produção comercial de mudas.

Para SOB120, nota-se valores altos tanto para o substrato VFC (94\%), quanto para o substrato BIO (89\%) (Figura 3F), concordando com Cruz-Silva et al. (2013), trabalhando com estacas de Jasminum mesnyi e com Gomes e Krinski (2016) com estacas de Piper umbellatum.

Com o uso da concentração de $0 \mathrm{mg} . \mathrm{L}^{-1}$, as miniestacas apresentaram-se com um maior porcentual de sobrevivência, com média de $97,5 \%$ considerando os dois substratos em conjunto. Embora essa sobrevivência na casa de vegetação não seja uma garantia de seu posterior enraizamento, esse é o principal fator para se alcançar tal objetivo, uma vez que as condições adequadas de umidade e temperatura garantem
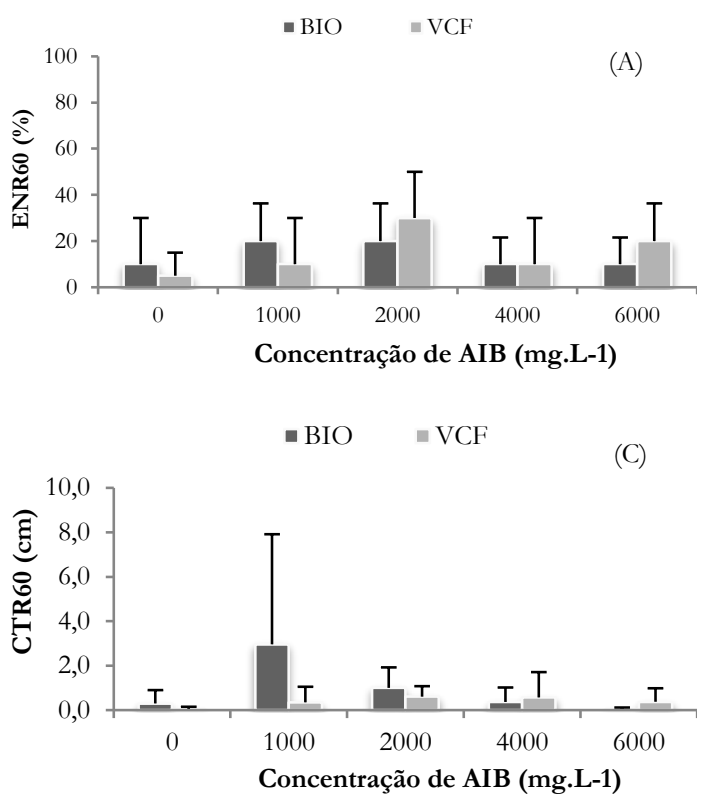

o turgor hídrico das estacas, além da não-manifestação de agentes patogênicos (Xavier et al. 2013).

O crescimento em H120 e DC120 foram também superiores para o substrato VFC com médias de $6,5 \mathrm{~cm}$ e 2,3 $\mathrm{mm}$ respectivamente (Figuras $3 \mathrm{G}$ e $3 \mathrm{H}$ ). Entre as concentrações de AIB, nota-se a superioridade da concentração $0 \mathrm{mg} . \mathrm{L}^{-1} \mathrm{com}$ médias de $6,5 \mathrm{~cm}$ para altura e 2,4 mm para diâmetro do coleto. Em relação ao PMSA120, o substrato VCF apresentou média de $380 \mathrm{mg}$ contra a média de $332 \mathrm{mg}$ para o substrato BIO (Figura 3I). Em relação à concentração de AIB, a concentração de 0 mg. $\mathrm{L}^{-1}$ apresentou, em geral, valores superiores às demais concentrações para o substrato BIO e para o substrato VCF, confirmando que não há necessidade de usar AIB em miniestacas a partir de mudas seminais de $H$. courbaril. O substrato VCF foi estatisticamente superior ao substrato BIO ( $\mathrm{P}<0,05$ pelo teste $\mathrm{F}$ ) quando se calculou o IQD120. Em relação à aplicação do AIB, o comportamento das miniestacas se mostrou, mais uma vez, prejudicado com a aplicação do regulador de crescimento, comprovados pelos valores superiores de 0,053 e 0,085 para as testemunhas nos substratos BIO e VFC respectivamente (Figura 3J). Os valores de IQD120 observados no presente estudo estão de acordo com os encontrados por Navroski et al. (2016) para Eucalyptus dunnii, e por Marana et al. (2015) para Jacaratia spinosa. Mudas vigorosas, com sistema radicular mais desenvolvido, apresentam maior probabilidade de sobreviver e crescer mais rápido em condições adversas de campo (Sampaio et al., 2010).

Neste sentido, a miniestaquia de $H$. courbaril, a partir de mudas seminais, é um método viável, tornando-se uma alternativa para produção de mudas desta espécie durante todo o ano, principalmente em situações onde a semente é um insumo limitante. Novos estudos devem ser realizados afim de aprimorar a técnica da miniestaquia para a espécie H. courbaril a fim de possibilitar a produção com fins comerciais
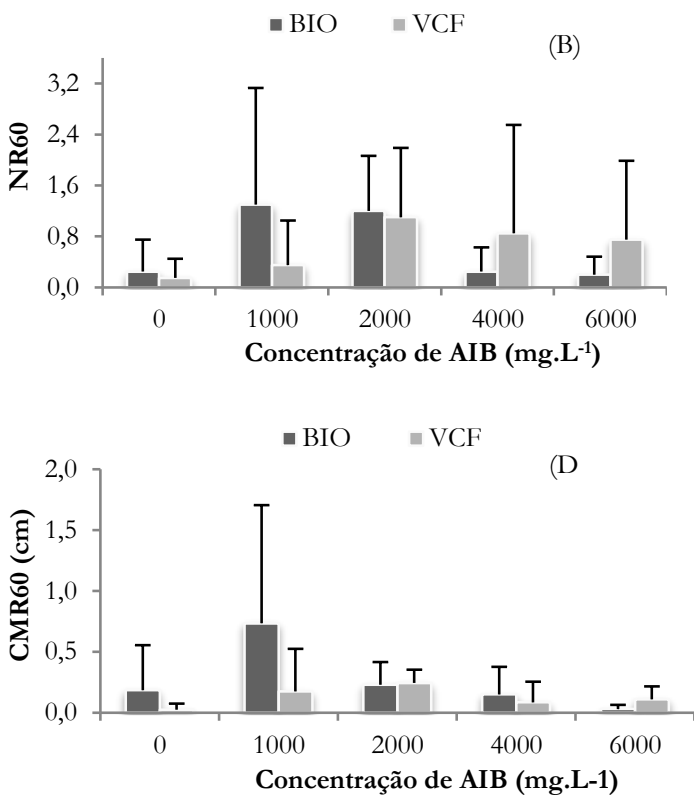

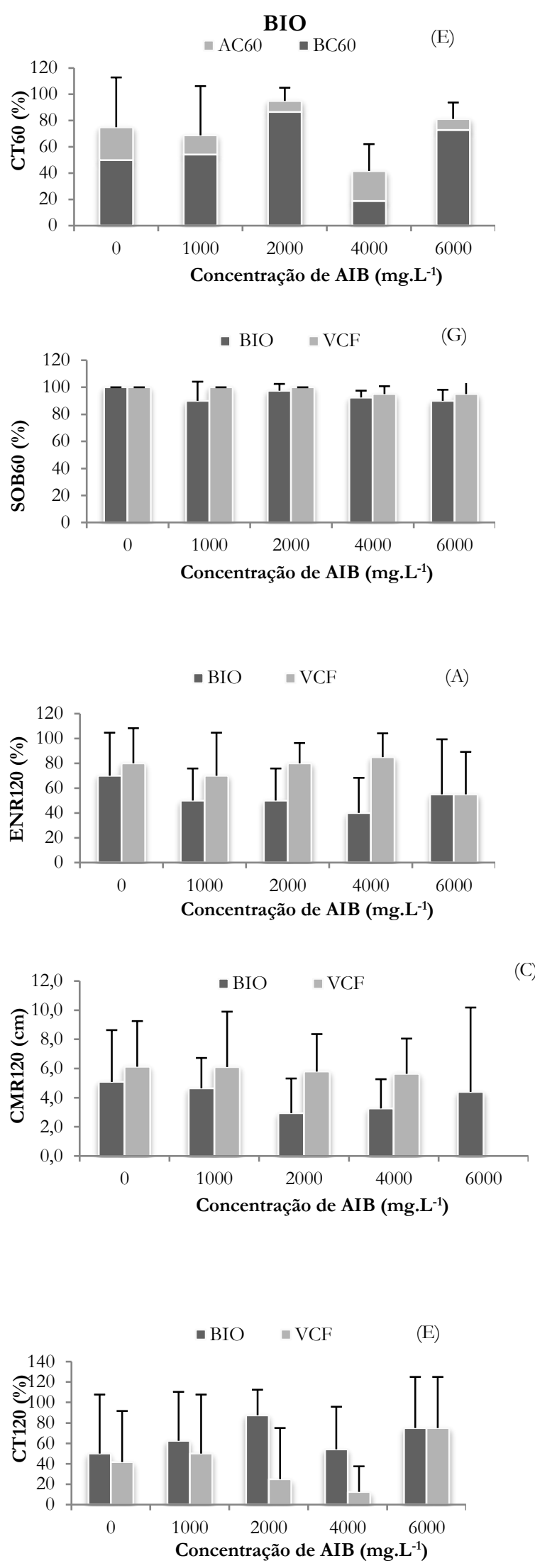

(C)
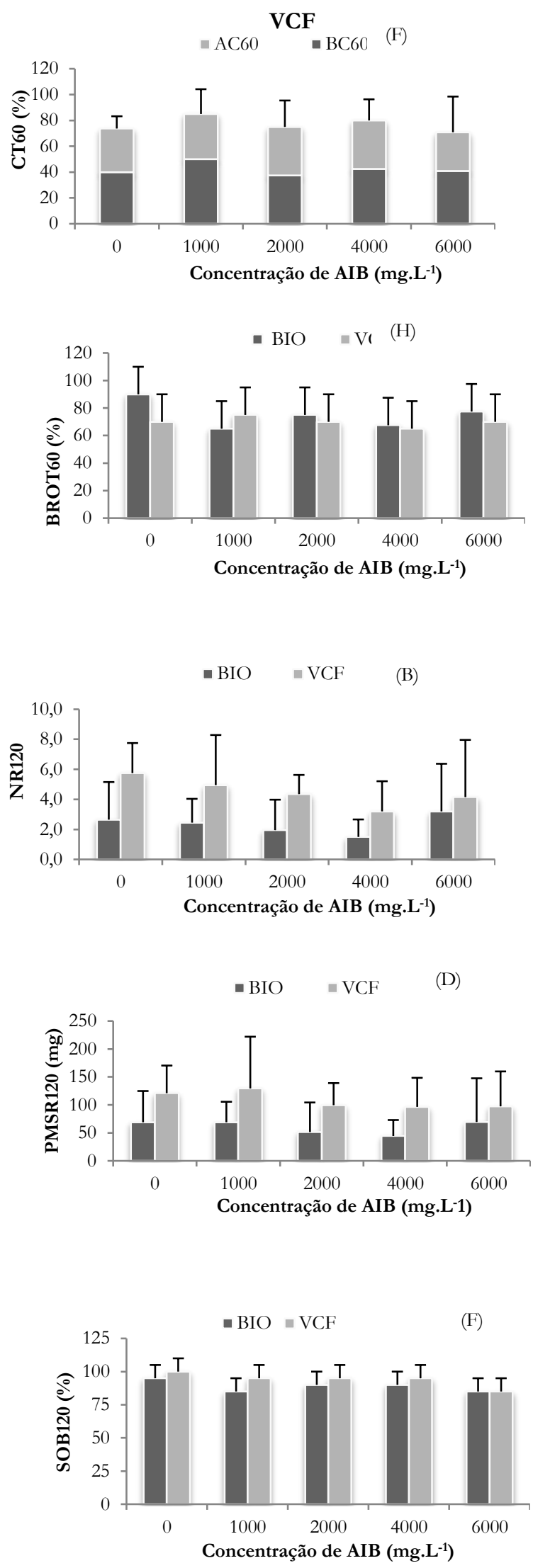

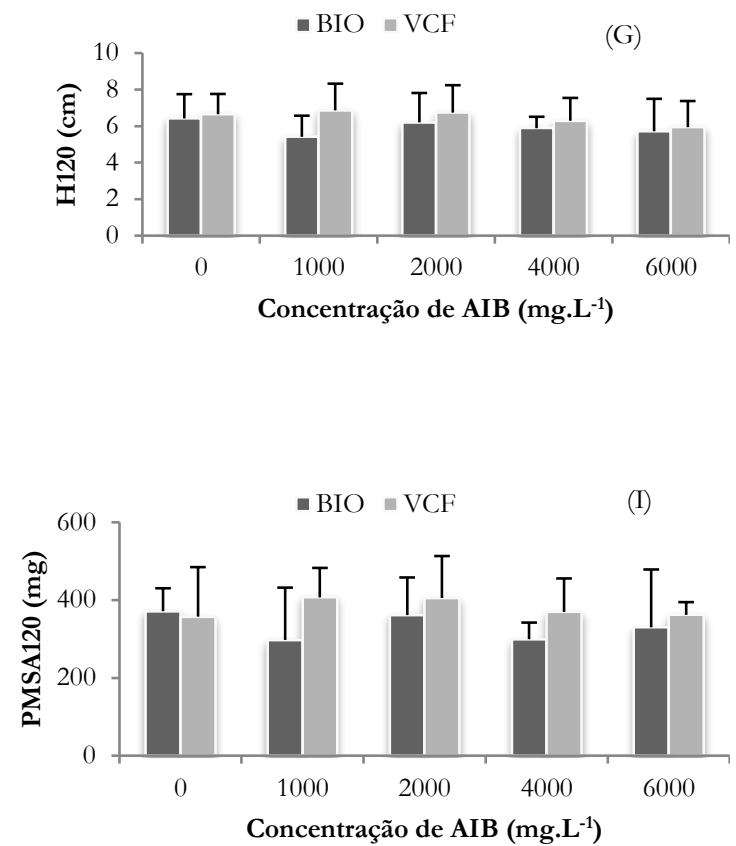
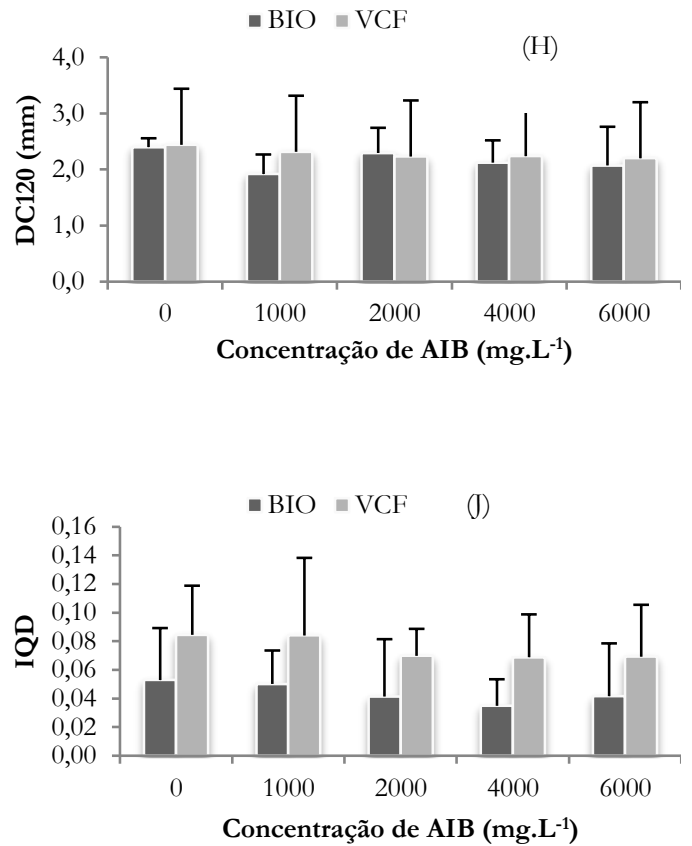

Figura 3 - Percentual de enraizamento (ENR120) (A), número de raízes (NR120) (B), comprimento total de raízes (CTR120) (C), peso da matéria seca radicular (PMSR120) (D), percentual de calogênese de miniestacas não enraizadas (CT120) (E), percentual de sobrevivência (SOB120) $(\mathrm{F})$, altura (H120) $(\mathrm{G})$, diâmetro do coleto (DC120) (H), peso da matéria seca aérea (PMSA120) (I) e índice de qualidade de Dickson (IDQ120) (J) de miniestacas de Hymenaea courbaril L., aos 120 dias de idades, em função das diferentes concentrações de AIB (0, 1000, 2000, 4000 e 6000 mg.L-1) e dos substratos Bioplant ${ }^{\circledR}$ (BIO) e composto - vermiculita + casca de arroz carbonizada + fibra de côco (VCF).

\section{Conclusões}

Com base nos objetivos propostos e nas condições em que foi realizado este estudo, pode-se concluir que:

- O substrato composto de $40 \%$ de vermiculita, $30 \%$ de casca de arroz carbonizada e $30 \%$ de fibra de coco mostrou-se eficiente para o enraizamento e crescimento de miniestacas de Hymenaea courbaril L.;

- Não é necessário o uso do regulador de crescimento AIB na propagação vegetativa de miniestacas de $H$. courbaril a partir de mudas seminais.

\section{Referências}

Almeida LPA, Alvarenga AA, Castro EM, Zanela SM, Vieira CV (2004) Crescimento inicial de plantas de Cryptocaria aschersoniana Mez. submetidas a níveis de radiação solar. Ciência Rural, 34(1):83-88.

Badilla Y, Xavier A, Murillo O, Paiva HN (2016) IBA efficiency on mini-cutting rooting from teak (Tectona grandis Linn F.) clones. Revista Árvore, 40(3):477485. Doi:10.1590/0100-67622016000300011

Brondani GE, Wendling I, Santin D, Benedetti EL, Roveda LF, Orrutéa AG (2007) Ambiente de enraizamento e substratos na miniestaquia de ervamate. Scientia Agraria, 8(3):257-267. Doi: 10.5380/rsa.v8i3.9540

Carvalho PER (2003) Espécies arbóreas brasileiras. Colombo: Embrapa-CNPF. Embrapa-SPI. 1039p.

Ciriello E, Mori ES (2015) Rooting of guanandi (Calophyllum brasiliense CAMBESS) cuttings using indole-butyric acid. Cerne, 21(4):641-648. Doi: 10.1590/010477602015210 41803

Correia ACG, Xavier A, Dias PC, Titon M, Santana RC (2015) Redução foliar em miniestacas e microestacas de clones híbridos de Eucalyptus globulus. Revista
Árvore, 39: 295-304. Doi.: 10.1590/010067622015000200009

Cruz ED, Pereira AC (2015) Germinação de sementes de espécies amazônicas: jatobá (Hymenaea courbaril L.). Comunicado técnico, Embrapa Amazonia Ocidental.

Cruz-Silva CTA, Fanti FP, Zuffellato-Ribas KC (2013) Propagação vegetativa de jasmim-amarelo (Jasminum mesnyi Hance) via estaquia. Scientia Agraria 14(2):7782. Doi: $10.5380 /$ rsa.v14i2.40935

Dias PC, Ataíde GM, Xavier A, Oliveira LS, Paiva HN (2015) Propagação vegetativa de Schizolobium amazonicum por estaquia. Cerne, 21(3):379-386. Doi: 10.1590/01047760201521031467

Dias PC, Xavier A, Oliveira LS, Correia ACG, Barbosa GA (2015b) Tipo de miniestaca e substratos na propagação vegetativa de angico-vermelho (Anadenanthera macrocarpa (Benth.) Brenan). Ciência Florestal, 25(4):909-919. Doi.: 10.5902/1980509820593

Endres L, Marroquim PMG, Santos CM, Souza NNF (2007) Enraizamento de estacas de Pau-Brasil (Caesalpinia echinata Lam.) tratadas com ácido indolbutírico e ácido naftaleno acético. Ciência Rural, 37(3):886-889. Doi: 10.1590/S010384782007000300046

Fachinello JC, Hoffmann A, Nachtigal JC (2005) Propagação de plantas frutíferas. Embrapa: Informação Tecnológica. 2005. $221 \mathrm{p}$.

Ferreira EB, Cavalcanti PP, Nogueira DA (2013) ExpDes: Experimental Designs pacakge. $\mathrm{R}$ package version 1.1.2. 2013. $42 \mathrm{p}$.

FLORA DO BRASIL (2020) em construção. Jardim Botânico do Rio de Janeiro. Disponível em: < 
http://floradobrasil.jbrj.gov.br/ >. Acesso em: 20 dez. 2018.

Freitas AF, Paiva HN, Xavier A, Neves JCL (2017) Proditividade de minicepas e enraizamento de miniestacas de híbridos de Eucalyptus globulus Labill. em resposta a nitrogênio Revista Árvore, 27: 193-202. Doi . 10.5902/198050987550

Gomes EM, Krinski D (2016) Propagação vegetativa de Piper umbellatum L. (Pipiraceae) em função de substratos e comprimento de estacas. Scientia Agraria, 17(3):31-37. Doi: 10.5380/rsa.v17i3.49695

Gomes JM, Couto L, Leite HG, Xavier A, Garcia SLR (2002) Parâmetros morfológicos na avaliação da qualidade de mudas de Eucalyptus grandis. Revista Árvore, 26(6):655-664.

Gomes MB, Faria AA, Cerqueira DS, Bailao LL (2013) Avaliação de métodos para superação de dormência de sementes de jatobá (Hymenaea courbaril L.). Interdisciplinar: Revista Eletrônica da Univar, 2(2):69.

Gonzaga LM, Silva SS, Campos AS, Ferreira RP, Campos ANR, Cunha ACMCM (2016) Evaluation of substrates and AMF sporulation in the production of seedlings of native forest species. Revista Árvore, 40(2):245-254. Doi: 10.1590/0100-67622016000200007

Hartmann HT, Kester DE, Daves JR FD, Geneve RL (2011) Plant propagation: principles and practices. 8 th ed. New Jersey: Prentice-Hall. 915p.

Marana JP, Miglioranza E, Ponseca EP (2015) Qualidade de mudas de jaracatiá submetidas a diferentes períodos de sombreamento em viveiro. Revista Árvore, 39(2):275-282. Doi: 10.1590/010067622015000200007

Navroski MC, Araujo MM, Reiniger LRS, Fior CS, Schfer G, Pereira MO (2016) Initial growth of seedlings of Eucalyptus dunnii Maiden as influenced by the addition of natural polymer and farming substrats. Revista Árvore, 40(4): 627-637. Doi: 10.1590/010067622016000400006

Nicknich R, Weiser AH, Zuffellato-Ribas KC (2013) Influencia do ácido indolbutírico no enraizamento de estacas de quaresmeira. Scientia Agraria, 14(2):65-67. Doi: $10.5380 /$ rsa.v14i2.40931

Oliveira AP (2002) Uso de ácido indolbutirico no enraizamento de estacas semilenhosas e lenhosas de pessegueiro. Dissertação. Universidade de Passo Fundo, Passo Fundo, 96p.

Pena ML, Zanette F, Biasi LA (2015) Miniestaquia a partir de minicepas originadas por enxertia de pitangueira adulta. Comunicata Scientiae, 6(3):397-306. Doi: 10.14295/CS.v6i3.817

Pereira DP, Moreira EFA, Machado ER, Mariano TS, Cunha FR (2017) Indolbutiric acid responses on rooting and survival of Hymenaea courbaril L. cuttings. Brazilian Journal of Applied Technology for Agricultural Science 10(2):111-117. Doi: 10.5935/PAeT.V10.N2.12

Pires P, Wendling I, Auer C, Brondani G (2015) Sazonalidade e soluções nutritivas na miniestaquia de Araucaria angustifolia (Bertol.) Kuntze. Revista
Árvore 39(2):283-293. Doi: 10.1590/010067622015000200008

R CORE TEAM MR (2017) A language and environment for statistical computing. R Foundation for Statistical Computing, Vienna, Austria.

Rossi T (2008) Identificação de Espécies Florestais: Hymenaea courbaril var. stilbocarpa (Jatobá). Instituto de Pesquisas e Estudos Florestais. Disponível em http://www.ipef.br/identificacao/hymenaea.courbaril.as p. Acesso em: 20 mar. 2017.

Sampaio PTB, Siqueira JAS, Costa S, Bruno FMS (2010) Propagação vegetativa por miniestacas de preciosa (Aniba canellila (H. B.K) MEZ). Acta Amazônica, 40(4):687-692.

Schmitz JAK, Souza PVD, Kämpf NA (2002)

Propriedades químicas e físicas de substratos de origem mineral e orgânica para o cultivo de mudas em recipientes. Ciência Rural, 32(6):937-944. Doi:10.1590/S0103-84782002000600005

Soares JM, Santos MMR, Candido CJ, Novello D (2016) Cookies adicionados de farinha de jatobá: composição química e análise sensorial entre crianças. Revista Brasileira de Pesquisa em Saúde 18(3):74-82.

Souza CC, Xavier A, Leite FP, Santana RC, Paiva HN (2014) Densidade de minicepas em minijardim clonal na produção de mudas de eucalipto. Pesquisa Florestal Brasileira, 34: 49-56. Doi: 10.4336/2014.pfb.34.77.512

Stuepp CA, Zuffellato-Ribas KC, Koehler HS, Wendling I (2015) Rooting mini-cuttings of Paulownia fortune var. mikado derived from clonal mini-garden. Revista Árvore, 39(3):497-504. Doi: 10.1590/010067622015000300010

Taiz L, Zeiger E (2017) Fisiologia vegetal. 7. ed. Porto Alegre: Artmed. 954 p.

Tracz AL, Wendling I, Kalil Filho AN, Santos AF, Quoirin MGG (2009) Enraizamento de perfilhos de pupunheira (Bactris gasipaes). Pesquisa Florestal Brasileira 58:67-73. Doi: 10.4336/2009/pfb.58.69

Vazques GH, Mesquita KAC (2003) Avaliação de diferentes substratos e doses de hormônio no enraizamento de estacas de ixora (Ixora coccínea $\mathrm{L}$. inn compacta). In: Congresso Brasileiro de Floricultura e Plantas Ornamentais e $1^{\circ}$ Congresso Brasileiro de cultura de tecidos de plantas. $101 \mathrm{p}$.

Wendling I, Dutra LF, Grossi F (2007) Produção e sobrevivência de miniestacas e minicepas de erva-mate cultivadas em sistema semi-hidropônico. Pesquisa Agropecuária Brasileira, 42(2):289-292. Doi: 10.1590/S0100-204X2007000200019

Wengling I, Brondani GE (2015) Vegetative rescue and cuttings propagation of Araucaria angustifolia (Bertol.) Kuntze. Revista Árvore, 39(1):93-104. Doi: 10.1590/0100-67622015000100009

Xavier A, Wendling I, Silva RL (2013) Silvicultura Clonal: Princípios e Técnicas. 2 ed. Viçosa: Editora UFV. 272 p. 